\title{
Burning Characteristics of Ammonium-Nitrate-Based Composite Propellants with a Hydroxyl-Terminated Polybutadiene/Polytetrahydrofuran Blend Binder
}

\author{
Makoto Kohga, Tomoki Naya, and Kayoko Okamoto \\ Department of Applied Chemistry, National Defense Academy, Hashirimizu 1-10-20, Yokosuka, Kanagawa 239-8686, Japan \\ Correspondence should be addressed to Makoto Kohga, kohga@nda.ac.jp
}

Received 5 December 2011; Accepted 24 January 2012

Academic Editor: Valsalayam Sanal Kumar

Copyright (c) 2012 Makoto Kohga et al. This is an open access article distributed under the Creative Commons Attribution License, which permits unrestricted use, distribution, and reproduction in any medium, provided the original work is properly cited.

\begin{abstract}
Ammonium-nitrate-(AN-) based composite propellants prepared with a hydroxyl-terminated polybutadiene (HTPB)/polytetrahydrofuran (PTHF) blend binder have unique thermal decomposition characteristics. In this study, the burning characteristics of $\mathrm{AN} / \mathrm{HTPB} / \mathrm{PTHF}$ propellants are investigated. The specific impulse and adiabatic flame temperature of an AN-based propellant theoretically increases with an increase in the proportion of PTHF in the HTPB/PTHF blend. With an AN/HTPB propellant, a solid residue is left on the burning surface of the propellant, and the shape of this residue is similar to that of the propellant. On the other hand, an AN/HTPB/PTHF propellant does not leave a solid residue. The burning rates of the AN/HTPB/PTHF propellant are not markedly different from those of the AN/HTPB propellant because some of the liquefied HTPB/PTHF binder cover the burning surface and impede decomposition and combustion. The burning rates of an AN/HTPB/PTHF propellant with a burning catalyst are higher than those of an AN/HTPB propellant supplemented with a catalyst. The beneficial effect of the blend binder on the burning characteristics is clarified upon the addition of a catalyst. The catalyst suppresses the negative influence of the liquefied binder that covers the burning surface. Thus, HTPB/PTHF blend binders are useful in improving the performance of AN-based propellants.
\end{abstract}

\section{Introduction}

Solid propellants are contained and stored in the combustion chamber of a solid rocket motor and are sometimes hermetically sealed in the chamber for long-term storage. Upon ignition, the propellants react to form hot gases within the chamber, which in turn are accelerated and ejected at a high velocity through a supersonic nozzle, thereby imparting momentum to the rocket motor. Solid rocket motors offer the advantage of having few moving parts. Therefore, they are used as propulsion systems for launch vehicles, spacecrafts, missiles, and other applications.

There are various types of solid propellants, and a suitable propellant is selected to meet the requirements of each rocket motor application. A composite propellant is a solid propellant in the form of heterogeneous propellant grains composed of oxidizer crystals held together in a matrix of a synthetic or plastic binder. Ammonium perchlorate
(AP) and hydroxyl-terminated polybutadiene (HTPB) are widely used as an oxidizer and a binder, respectively, because AP/HTPB-based propellants have excellent burning and mechanical characteristics. One of the few serious drawbacks of AP-based propellants are the products of combustion, such as $\mathrm{HCl}$, chlorine, and chlorine oxides, which cause atmospheric pollution.

Recently, ammonium-nitrate-(AN-) based composite propellants, that is, propellants prepared with $\mathrm{AN}$ as the oxidizer, have become popular, although there are some major problems associated with their use. These problems include a low burning rate, poor ignitability, and low energy output compared to AP-based propellants [1,2]. Despite these problems, AN-based propellants are popular because they are chlorine-free, present a small hazard, and have low observable emissions (minimum smoke). Numerous approaches have been adopted to improve the burning characteristics of AN-based propellants, including the use of 
catalysts [3-9], the addition of metals [10-13], and the use of energetic binders based on azide polymers [14-20].

Applying an energetic binder is an effective approach toward AN-based propellants. However, the synthesis processes of energetic binders are complicated and costly; therefore, it is difficult to manufacture these binders industrially. To date, such energetic binders have not yet been used for practical applications because they are expensive.

Polytetrahydrofuran (PTHF) is used as an ingredient in making rubber products. This inexpensive polymer is massproduced commercially in several molecular weights. Table 1 shows the chemical properties of PTHF and HTPB. Although PTHF is not an energetic material, it could be a useful binder to improve the burning characteristics of composite propellants because oxygen is present in the repeating unit of PTHF as opposed to HTPB in which oxygen is not present [21-23]. The chemical structure of PTHF is similar to that of HTPB, and therefore, PTHF should mix easily and uniformly with HTPB.

The curing behavior, mechanical properties, and thermal decomposition behavior of HTPB binders are improved by the addition of a small amount of PTHF. PTHF is an effective plasticizer in the preparation of high-performance composite propellants $[24,25]$. Furthermore, compared to HTPB, HTPB/PTHF blends have preferable curing behaviors and tensile properties for use as binders [26]. Therefore, it is expected that a HTPB/PTHF blend will prove to be a useful binder ingredient for improving the performance of $\mathrm{AN}$ based composite propellants.

The thermal decomposition behaviors of AN-based composite propellants with a HTPB/PTHF-blend binder are provided in [27]. The thermal decomposition of AN/HTPB/PTHF propellants occurs at lower temperatures than that of AN/HTPB propellants according to the results of thermogravimetry/differential thermal analysis (TG-DTA). According to a visual observation of the decomposition phenomena, the propellants had decomposed significantly and the generation of smoke was more vigorous in the temperature range of $530-550 \mathrm{~K}$. The size of the black residue after decomposition was smaller than that of the propellant sample before heating. The AN in the propellant decomposed completely, and the quantity of liquefied or decomposed binder increased with an increase in the mass ratio $(\xi)$ of PTHF in the binder. AN/HTPB/PTHF propellants were found to have unique thermal decompositions. In this study, the burning characteristics of AN/HTPB/PTHF propellants were examined and reported.

\section{Experimental}

2.1. Sample Ingredients. AN was ground in a vibration ball mill (for $5 \mathrm{~min}$ ) for use as an oxidizer. The weight mean diameter of AN was $125 \mu \mathrm{m}$. PTHF and HTPB were used as binder materials. HTPB is a widely used binder and composite propellant, while PTHF is produced in several molecular weights. In this study, three types of PTHF with sample molecular weights of 650, 1400, and 2900 designated as PTHF1, PTHF2, and PTHF3, respectively, were used. The value of the symbol increased with increasing molecular weight. Isophorone diisocyanate (IPDI) was used as the curing agent. The ratio of the NCO group of IPDI to the $\mathrm{OH}$ group of HTPB and PTHF was 1.2.

The values of $\xi$ were $0,0.2,0.4,0.6$, and 0.8 . Table 2 shows the binder formulations. A binder at $\xi=1$ was not prepared in this study because the burning rate characteristics of an AN-based propellant at $\xi=1$ are provided in [23]. PTHF did not become solid by using IPDI alone, but it did become sufficiently rubbery by adding glycerin as a crosslinking modifier such that it could be used as a binder. In this study, the burning characteristics of an AN-based propellant with a HTPB/PTHF blend binder were not compared with those of a propellant at $\xi=1$ because the addition of glycerin would make the comparison inconsistent.

Ammonium dichromate (ADC) was used as a burning catalyst and added to the propellant at $6 \%$ [8]. The weight mean diameter of ADC was $61 \mu \mathrm{m}$.

2.2. Burning Rate Measurement. Each of the prepared propellant strands were $10 \mathrm{~mm}$ in diameter and $40 \mathrm{~mm}$ in length. The burning behavior was investigated in a chimneytype strand burner that was pressurized with nitrogen. Each strand was ignited by applying $10 \mathrm{~V}$ to an electrically heated wire threaded into the top of the strand. The temperature of the wire was above $1200 \mathrm{~K}$. Each propellant strand was combusted within a pressure range of $0.5-7 \mathrm{MPa}$. The burning phenomenon of the propellant was recorded by a highspeed video recorder, and the burning rate was measured from the images obtained. The combustion phenomenon was recorded at a shutter speed of 30-125 frames $\mathrm{s}^{-1}$. All measurements were checked in triplicate at each pressure, and the average values were used in the data analysis.

\section{Results and Discussion}

3.1. Theoretical Performance. The specific impulse $\left(I_{\mathrm{sp}}\right)$ and adiabatic flame temperature $\left(T_{f}\right)$ of the propellants at $70 \%$ and $80 \%$ AN were calculated using the NASA CEA program [28] with a combustion pressure of $7 \mathrm{MPa}$, an exit pressure of $0.1 \mathrm{MPa}$, and an initial temperature of $298 \mathrm{~K}$. Table 3 shows the values of $I_{\mathrm{sp}}$ and $T_{f}$. The values of $I_{\mathrm{sp}}$ and $T_{f}$ increase with an increase in $\xi$, and at constant $\xi$, these values slightly increase with a decrease in the molecular weight of PTHF. The propellant performance is theoretically dependent upon the $\xi$ value and the molecular weight of PTHF. In particular, the increases in the values of the propellant at $80 \% \mathrm{AN}$ are greater than those of the propellant at $70 \%$ AN. For example, the maximum difference in $I_{\text {sp }}$ between $\xi=0$ and 0.8 at $80 \%$ $\mathrm{AN}$ is $5 \mathrm{~s}$, whereas that at $70 \% \mathrm{AN}$ is $3 \mathrm{~s}$. The maximum difference in $T_{f}$ between $\xi=0$ and 0.8 at $80 \% \mathrm{AN}$ is $200 \mathrm{~K}$, whereas that at $70 \% \mathrm{AN}$ is $31 \mathrm{~K}$. These values were obtained for an AN/HTPB/PTHF1 propellant. These results suggested that the effect of PTHF on propellant performance would be enhanced by the use of a smaller molecular weight of PTHF at $80 \%$ AN.

The mass fraction of IPDI in the binder increases with decreasing molecular weight of PTHF, as shown in Table 2. For example, at $\xi=0.8$, the mass fraction of IPDI for the PTHF1 binder is $25.6 \%$ and that for the PTHF3 binder is 
TABLE 1: Chemical properties of PTHF and HTPB.

\begin{tabular}{lcc}
\hline Binder ingredient & $\mathrm{PTHF}$ & $\mathrm{HTPB}$ \\
\hline Molecular structure & $\mathrm{HO}-\left(-\mathrm{CH}_{2}-\mathrm{CH}_{2}-\mathrm{CH}_{2}-\mathrm{CH}_{2}-\mathrm{O}-\right)_{n}-\mathrm{H}$ & $\mathrm{HO}-\left(-\mathrm{CH}_{2}-\mathrm{CH}_{2} \mathrm{CH}-\mathrm{CH} \mathrm{CH}_{2}-\right)_{n}-\mathrm{OH}$ \\
Density $\left(\mathrm{g} \mathrm{cm}^{-3}\right)$ & $0.970-0.981$ & 0.902 \\
Heat of formulation $\left(\mathrm{kJ} \mathrm{mol}^{-1}\right)$ & -219.2 & -21.1 \\
\hline
\end{tabular}

TABLe 2: Binder formulations.

\begin{tabular}{lcccc}
\hline \multirow{2}{*}{ Binder } & $\xi$ & \multicolumn{3}{c}{ Mass fraction $(\%)$} \\
& $(-)$ & HTPB & PTHF & IPDI \\
\hline \multirow{4}{*}{ PTHF1 } & 0 & 92.5 & 0.0 & 7.5 \\
& 0.2 & 69.7 & 17.4 & 12.8 \\
& 0.4 & 49.5 & 32.9 & 17.6 \\
& 0.6 & 31.3 & 46.9 & 21.8 \\
& 0.8 & 14.9 & 59.5 & 25.6 \\
\hline \multirow{5}{*}{ PTHF2 } & 0 & 92.5 & 0.0 & 7.5 \\
& 0.2 & 72.5 & 18.1 & 9.4 \\
& 0.4 & 53.3 & 35.6 & 11.1 \\
& 0.6 & 34.9 & 52.3 & 12.8 \\
& 0.8 & 17.1 & 68.5 & 14.4 \\
\hline \multirow{5}{*}{ PTHF3 } & 0 & 92.5 & 0.0 & 7.5 \\
& 0.2 & 73.8 & 18.5 & 7.7 \\
& 0.4 & 55.3 & 36.8 & 7.9 \\
& 0.6 & 36.8 & 55.2 & 8.1 \\
& 0.8 & 18.4 & 73.4 & 8.2 \\
\hline
\end{tabular}

$8.2 \%$. For the $80 \%$ AN propellant at $\xi=0.8$, the difference in $I_{\mathrm{sp}}$ and $T_{f}$ between the AN/HTPB/PTHF1 propellant and the AN/HTPB/PTHF3 propellant is $1 \mathrm{~s}$ and $35 \mathrm{~K}$, respectively. This indicates that the influence of the IPDI fraction on propellant performance is negligible.

The value of $I_{\mathrm{sp}}$ theoretically increases with the use of PTHF, indicating that PTHF would be effective in enhancing the performance of an AN-based propellant. The increase in $T_{f}$ would also accelerate the propellant combustion reactions. Therefore, the burning rate of the AN/HTPB propellant would be expected to increase with increasing $\xi$.

Table 4 shows the theoretical mole fraction of the main combustion products from the AN/HTPB/PTHF2 propellants; these products were scarcely dependent on the molecular weight of PTHF. For the $70 \%$ AN propellant, the mole fraction of graphite notably decreases with the addition of PTHF as a binder, and the fraction of other products increases with an increase in $\xi$. For the $80 \%$ AN propellant, no graphite is produced. The mole fraction of $\mathrm{H}_{2} \mathrm{O}$ increases with an increase in $\xi$, whereas the fractions of $\mathrm{CH}_{4}, \mathrm{CO}$, $\mathrm{CO}_{2}, \mathrm{H}_{2}$, and $\mathrm{N}_{2}$ decrease, indicating that the hydrogen produced by the propellant decomposition would react with the oxygen in PTHF. The oxygen contained in PTHF was found to influence the reaction product compositions and cause an increase in $I_{\text {sp }}$ and $T_{f}$.

A subsequent experiment investigated the thermal decomposition behavior and burning characteristics of propellants at $80 \% \mathrm{AN}$, because the influence of the HTPB/PTHF binder on the theoretical performance of a propellant at $80 \% \mathrm{AN}$ is greater than that of a propellant at $70 \%$ AN.

3.2. Burning Rate of Propellant. Figure 1 shows the burning rate characteristics of AN/HTPB/PTHF propellants. These propellants only burned at pressures above $2 \mathrm{MPa}$. The burning rates are seen to increase linearly on the logarithmic scale. The pressure exponent of these propellants is in the range of $0.7-0.8$, and the values are not correlated with $\xi$ and the molecular weight of PTHF. There is no obvious difference in the burning rates of the AN/HTPB/PTHF and AN/HTPB propellants.

The thermal decomposition behavior of the AN/HTPB/ PTHF propellant $(\xi=0.2-0.8$ ) was preferable for creating a high burning rate propellant because the decomposition temperature ranges of the $\mathrm{AN} / \mathrm{HTPB} / \mathrm{PTHF}$ propellant were lower than those of the AN/HTPB propellant $(\xi=0)$ [26]. The $T_{f}$ for the AN/HTPB/PTHF propellant was higher than that for the AN/HTPB propellant, as described in the previous section. These results suggest that the burning rate would increase by the use of PTHF as a binder; however, the burning rates of the AN/HTPB/PTHF propellant were not significantly different from those of the AN/HTPB propellant, as shown in Figure 1.

The burning propellant at $7 \mathrm{MPa}$ was quenched by a depressurization of approximately $-1 \mathrm{MPa} \mathrm{s}^{-1}$. Figure 2 shows photographs of the AN/HTPB/PTHF2 propellant at $\xi$ $=0$ and 0.6 after quenching. With the AN/HTPB propellant $(\xi=0)$, there was solid residue on the burning surface, and the shape of the residue was almost the same as that of the propellant. Theoretically, the propellant with $80 \%$ AN should not generate graphite, as described in Section 3.1. However, in actual, this propellant did produce a residue after the burning test, indicating that the actual propellant combustion is inferior to the theoretical one. This is because the theoretical values were calculated for an adiabatic process, while in actual combustion the propellant sample burned in a nitrogen gas flow, resulting in heat loss and mass transfer into/from the system.

On the other hand, the propellant containing PTHF did not leave a solid residue at $\xi=0.6$, as shown in Figure 2(b). A small amount of solid residue was generated by burning, but this was removed from the burning surface and discharged from the combustion chamber along with nitrogen.

When a solid residue is produced in the combustion chamber of a rocket motor, it interferes with the combustion of the propellant and the mass ratio of the rocket decreases. Furthermore, the presence of a solid residue results in erosion of the nozzle and an exhaust plume is produced. Thus, the generation of a solid residue is undesirable. The use of PTHF as a binder ingredient prevents the generation of a solid 
TABLE 3: Theoretical values of $I_{\text {sp }}$ and $T_{f}$.

\begin{tabular}{|c|c|c|c|c|c|c|}
\hline \multirow{2}{*}{$\begin{array}{l}\text { Propellant } \\
\text { AN content (\%) }\end{array}$} & \multicolumn{2}{|c|}{ AN/HTPB/PTHF1 } & \multicolumn{2}{|c|}{ AN/HTPB/PTHF2 } & \multicolumn{2}{|c|}{ AN/HTPB/PTHF3 } \\
\hline & 70 & 80 & 70 & 80 & 70 & 80 \\
\hline$\xi(-)$ & \multicolumn{6}{|c|}{$I_{\mathrm{sp}}(\mathrm{s})$} \\
\hline 0 & 189 & 198 & 189 & 198 & 189 & 198 \\
\hline 0.2 & 190 & 199 & 189 & 199 & 189 & 199 \\
\hline 0.4 & 190 & 201 & 190 & 200 & 190 & 200 \\
\hline 0.6 & 191 & 202 & 191 & 201 & 191 & 201 \\
\hline 0.8 & 192 & 203 & 191 & 203 & 191 & 202 \\
\hline$\xi(-)$ & \multicolumn{6}{|c|}{$T_{f}(\mathrm{~K})$} \\
\hline 0 & 1186 & 1353 & 1186 & 1353 & 1186 & 1353 \\
\hline 0.2 & 1194 & 1403 & 1191 & 1393 & 1190 & 1388 \\
\hline 0.4 & 1200 & 1456 & 1197 & 1438 & 1195 & 1429 \\
\hline 0.6 & 1208 & 1507 & 1203 & 1485 & 1200 & 1473 \\
\hline 0.8 & 1217 & 1553 & 1210 & 1531 & 1207 & 1518 \\
\hline
\end{tabular}

TABLE 4: Theoretical mole fraction of main combustion products of AN/HTPB/PTHF2 propellants.

\begin{tabular}{|c|c|c|c|c|c|c|c|}
\hline \multicolumn{8}{|c|}{$70 \% \mathrm{AN}$} \\
\hline \multirow{2}{*}{$\xi(-)$} & \multicolumn{7}{|c|}{ Mole fraction $(-)$} \\
\hline & $\mathrm{CH}_{4}$ & $\mathrm{CO}$ & $\mathrm{CO}_{2}$ & $\mathrm{H}_{2}$ & $\mathrm{H}_{2} \mathrm{O}$ & $\mathrm{N}_{2}$ & Graphite \\
\hline 0 & 0.0843 & 0.0358 & 0.1270 & 0.2397 & 0.2086 & 0.1653 & 0.1393 \\
\hline 0.2 & 0.0852 & 0.0364 & 0.1338 & 0.2411 & 0.2156 & 0.1681 & 0.1198 \\
\hline 0.4 & 0.0862 & 0.0368 & 0.1406 & 0.2423 & 0.2227 & 0.1709 & 0.1005 \\
\hline 0.6 & 0.0873 & 0.0371 & 0.1473 & 0.2433 & 0.2299 & 0.1737 & 0.0814 \\
\hline 0.8 & 0.0885 & 0.0374 & 0.1541 & 0.2440 & 0.2371 & 0.1765 & 0.0624 \\
\hline \multicolumn{8}{|c|}{$80 \% \mathrm{AN}$} \\
\hline \multirow{2}{*}{$\xi(-)$} & \multicolumn{7}{|c|}{ Mole fraction $(-)$} \\
\hline & $\mathrm{CH}_{4}$ & $\mathrm{CO}$ & $\mathrm{CO}_{2}$ & $\mathrm{H}_{2}$ & $\mathrm{H}_{2} \mathrm{O}$ & $\mathrm{N}_{2}$ & Graphite \\
\hline 0 & 0.0662 & 0.0507 & 0.1719 & 0.2642 & 0.2371 & 0.2099 & 0 \\
\hline 0.2 & 0.0581 & 0.0469 & 0.1700 & 0.2636 & 0.2521 & 0.2093 & 0 \\
\hline 0.4 & 0.0506 & 0.0434 & 0.1680 & 0.2620 & 0.2672 & 0.2088 & 0 \\
\hline 0.6 & 0.0437 & 0.0401 & 0.1659 & 0.2596 & 0.2822 & 0.2085 & 0 \\
\hline 0.8 & 0.0373 & 0.0370 & 0.1637 & 0.2564 & 0.2974 & 0.2082 & 0 \\
\hline
\end{tabular}

residue for the AN/HTPB propellant, although the burning rate of the propellant does not increase, indicating that PTHF improves the propellant performance.

Figure 3 shows scanning electron microscopy (SEM) photographs of the burning surface of a propellant quenched at $\xi=0$ and 0.6 . In Figure 3(a), the burning surface of the quenched AN/HTPB propellant $(\xi=0)$ has a spongelike appearance. What appear to be voids in the sponge are traces of AN particles caused by the HTPB binder being barely liquefied just before decomposition [23-27]. The AN particles exposed at the burning surface decomposed and disappeared during the depressurization event. A trace amount of AN was observed at the bottom. The HTPB at the burning surface barely liquefied and maintained its shape just before decomposition. Because the shape of the binder was preserved, the AN particles were exposed at the burning surface and decomposition gases were emitted in the gas phase.

Figure 3(b) shows the burning surface of the quenched AN/HTPB/PTHF2 propellant $(\xi=0.6)$, which is basically smooth and wavy. When the melted AN at the burning surface was cooled to the surrounding temperature, the AN crystallized and numerous cracks were generated in the AN crystals owing to phase transitions. As described above, the burning surface was smooth, indicating that a majority of materials at the burning surface were binder ingredients. The depressions depict the traces of the decomposition of AN particles and also some projections at the burning surface. The AN particles were below the surface of these projections; small holes were produced by ejection of the decomposed 


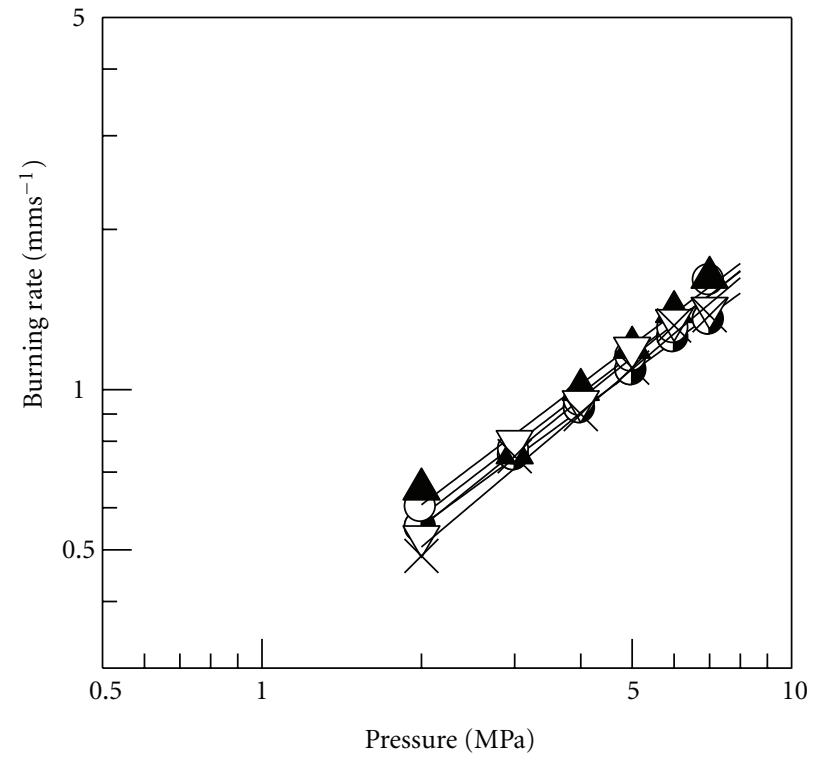

(a) AN/HTPH/PTHF1

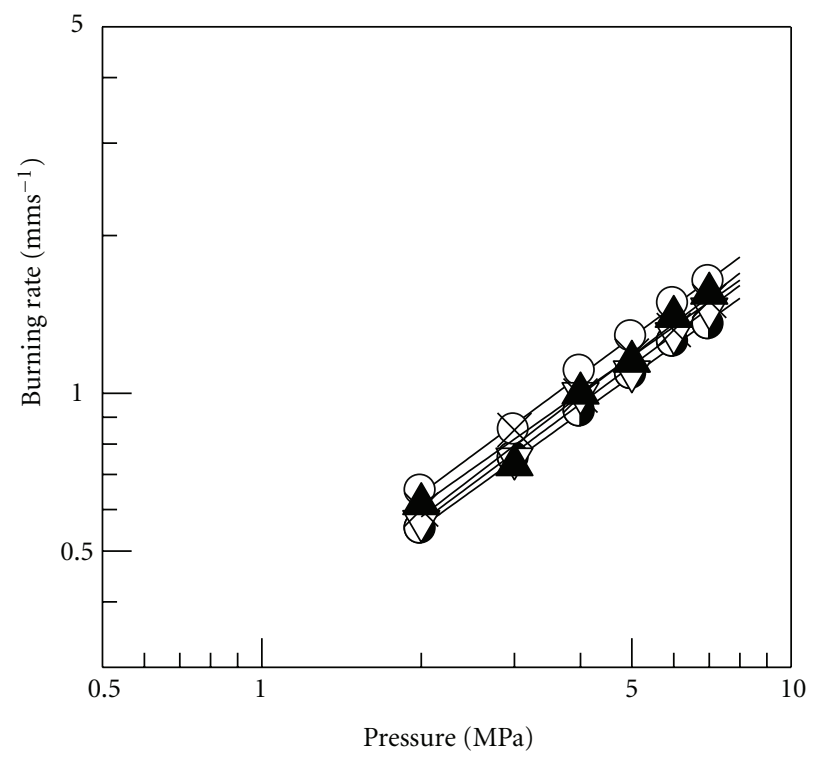

(b) AN/HTPH/PTHF2
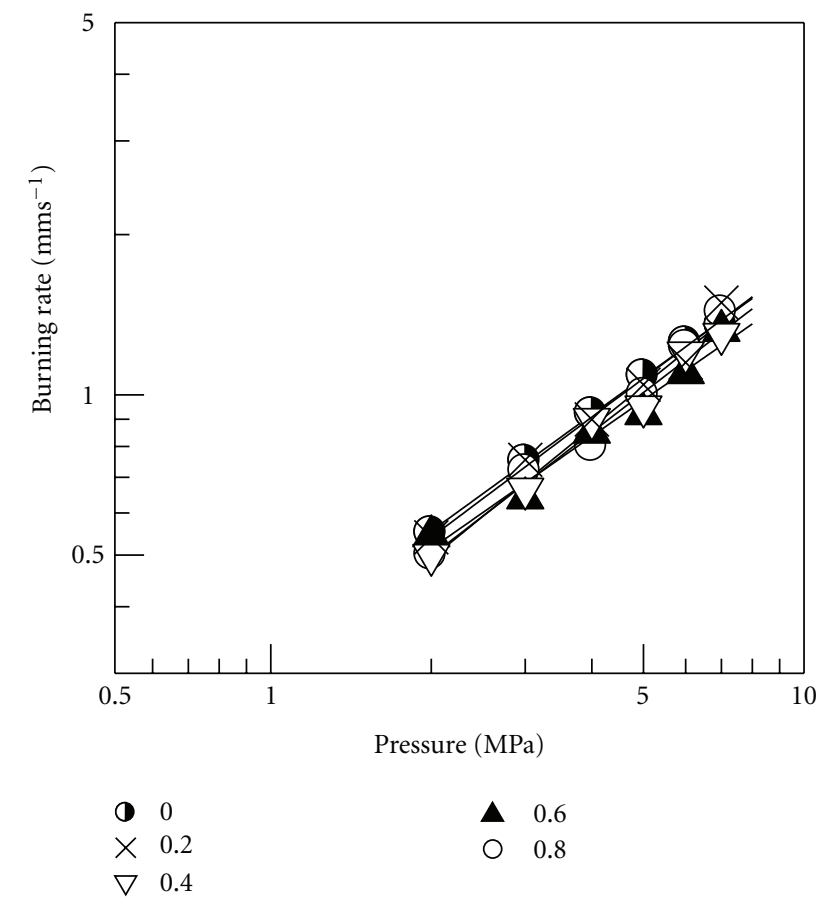

(c) AN/HTPH/PTHF3

FIGURE 1: Burning rate characteristics of propellants.

gases of AN trapped under the surface. Part of the AN particles was observed at the surface of the projections.

As described in Section 3.1, the value of $T_{f}$ was increased by adding PTHF. The increase in $T_{f}$ accelerates the propellant combustion reaction and enhances the temperature gradient just above the burning surface; the burning rate of the AN/HTPB propellant would therefore be expected to increase by the addition of PTHF. It was hypothesized that the burning rates of the AN/HTPB/PTHF propellant were not noticeably different from those of the AN/HTPB propellant for physical rather than chemical reasons.

The combustion process of the AN/HTPB propellant is as follows [23]. At the burning surface, AN melts and decomposes, while the HTPB binder barely liquefies and retains its shape until just before decomposition. A condensed phase is formed by the melted AN and the solid HTPB binder just below the burning surface. The decomposition gases of the AN and HTPB binder are diffused in the gas phase 


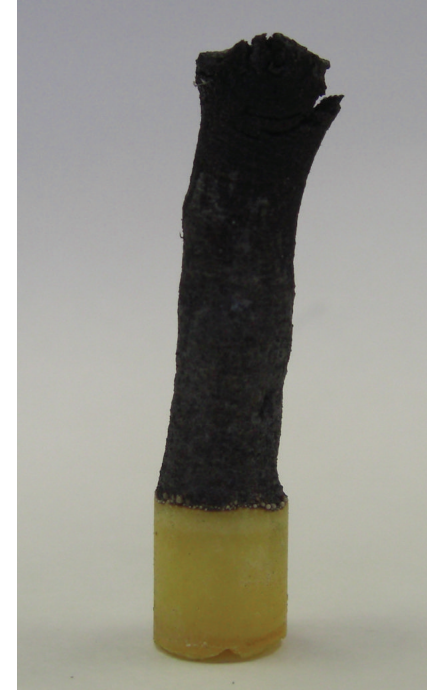

(a) AN/HTPB propellant $(\xi=0)$

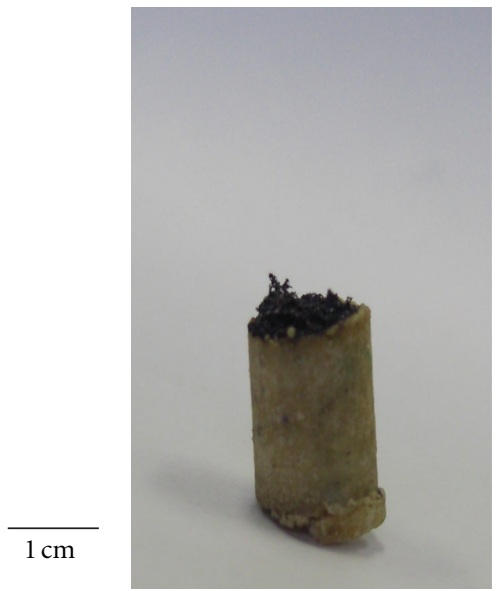

(b) AN/HTPB/PTHF2 propellant $(\xi=0.6)$

FIGURE 2: Photograph of propellant quenched at $7 \mathrm{MPa}$.

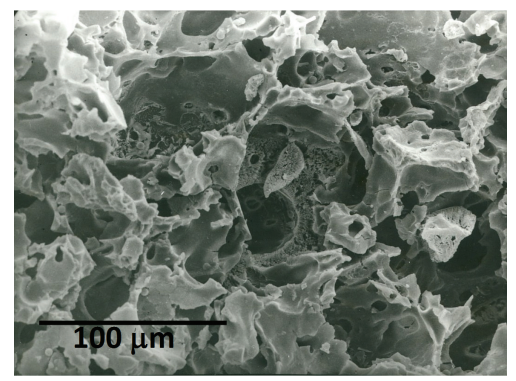

(a) AN/HTPB propellant $(\xi=0)$

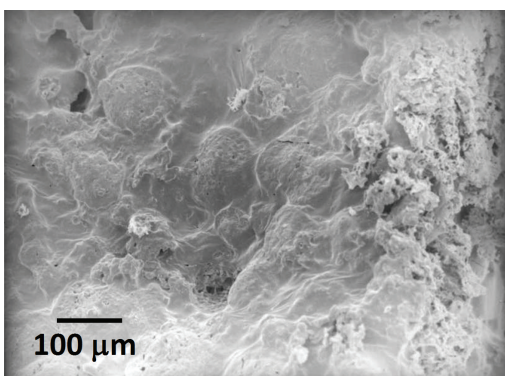

(b) AN/HTPB/PTHF2 propellant $(\xi=0.6)$

FIGURE 3: SEM photographs of burning surface of propellant quenched at $7 \mathrm{MPa}$.

and burned. A large quantity of heat is produced by the combustion of the decomposition gases, and this heat is fed back to the burning surface of the propellant, thus increasing the surface temperature even more. Combustion of the AN/HTPB propellant is maintained by this sequence of processes. During this sequence of events, $\mathrm{AN}$ is continually exposed on the burning surface.

For the AN/PTHF/glycerin propellant, the liquefied binder covering the burning surface interferes with the evolution of the AN decomposition gases and the heat flux feedback from the flame to $\mathrm{AN}$, and therefore, the AN/PTHF/glycerin propellant does not ignite [23]. It was found that an AN-based propellant does not burn when the burning surface is covered with a liquefied binder, which prevents AN from being exposed.

In a previous study [27], at $\xi=0.6$ and 0.8 , a small quantity of HTPB/PTHF-blended binders liquefied at approximately $474 \mathrm{~K}$, and that of AN/HTPB/PTHF propellants liquefied at approximately $500 \mathrm{~K}$. As described above, most of the materials at the burning surface are binder ingredients. This suggests that the burning rates of the AN/HTPB/PTHF propellant are not higher than those of the AN/HTPB propellant because some portion of the liquefied $\mathrm{HTPB} / \mathrm{PTHF}$ binder covered the burning surface.

3.3. Burning Rate of Propellant Supplemented with ADC. The effect of a PTHF/glycerin binder on improving the burning characteristics of an AN/PTHF/glycerin propellant was clarified by adding ADC, which suppressed the negative influence of the liquefied binder covering the burning surface [23]. The AN/HTPB/PTHF propellants were supplemented with $\mathrm{ADC}$, and the burning rates of these propellants were measured.

Figure 4 shows the burning rate characteristics of AN/HTPB and AN/HTPB/PTHF propellants with ADC. These propellants were successfully burned above $0.5 \mathrm{MPa}$ by the addition of ADC and the burning rates increased linearly on the logarithmic scale. The pressure exponent of these 


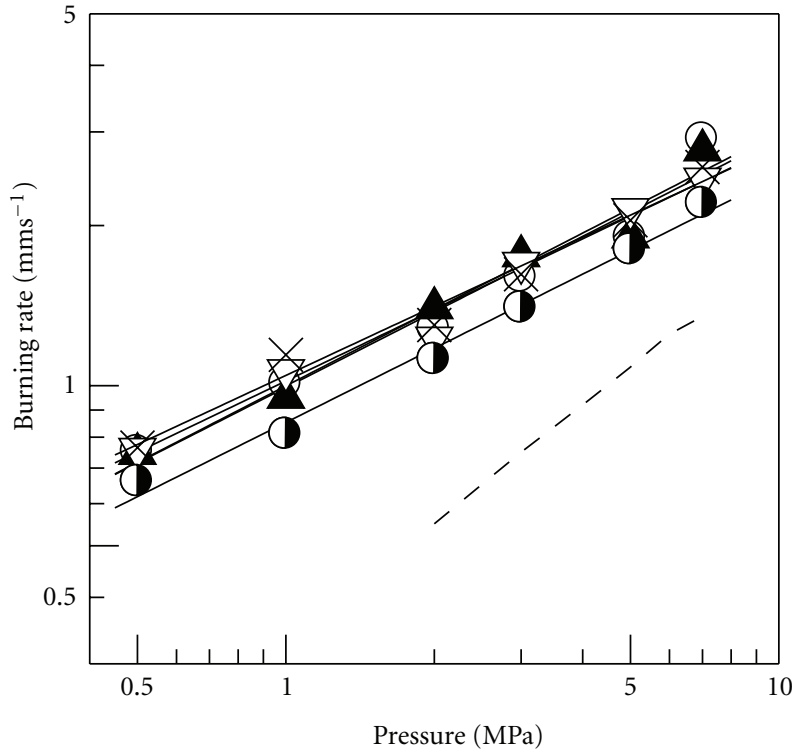

(a) AN/HTPH/PTHF1

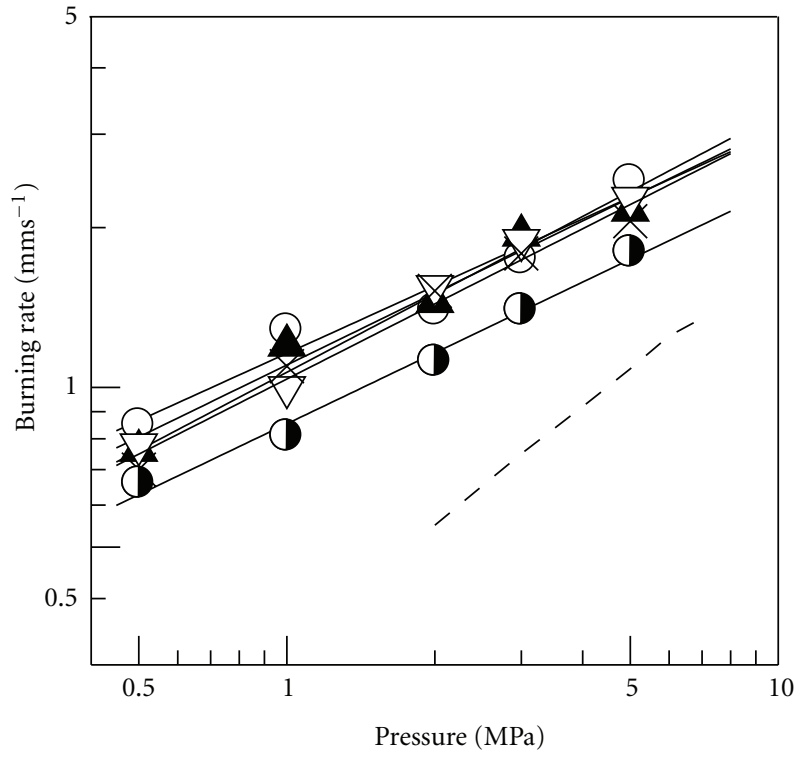

(b) AN/HTPH/PTHF2
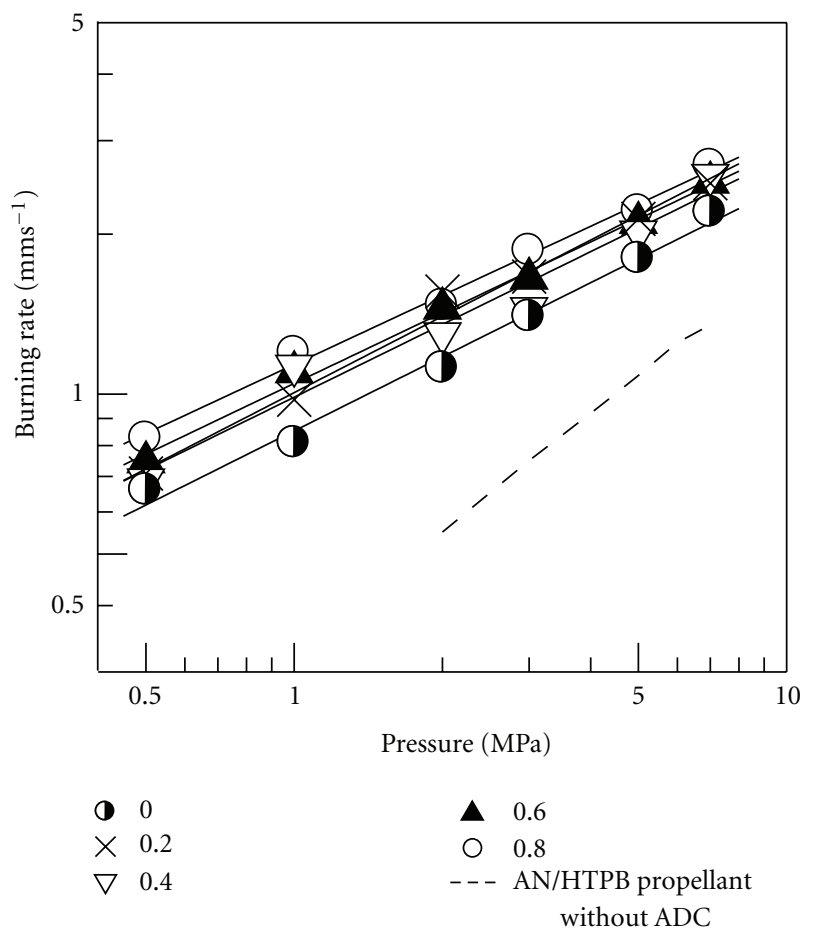

(c) AN/HTPH/PTHF3

FIGURE 4: Burning rate characteristics of propellants with ADC.

propellants was approximately 0.6 and the type of binder did not influence the values. As described above, the pressure exponent of the propellants without ADC was in the range of 0.7-0.8. The pressure exponent of the propellant with ADC was lower than that of the propellant without it.

The burning rates of an AN/HTPB propellant without ADC, as shown in Figure 1, are also illustrated in
Figure 4 with broken lines for comparison. The burning rates of propellants with ADC were higher than those of propellants without ADC. Furthermore, the burning rates of AN/HTPB/PTHF propellants with ADC were approximately 1.3 times those of AN/HTPB propellants with ADC. The effect of the HTPB/PTHF blend on the improvement of the burning characteristics is clarified by adding ADC because 
it suppressed the negative influence of the liquefied binder covering the burning surface. However, the burning rate of the AN-based propellant with the HTPB/PTHF blend as a binder was clearly not dependent on $\xi$ and the molecular weight of PTHF.

\section{Conclusions}

The burning characteristics of an AN-based propellant with a HTPB/PTHF blend binder were investigated. The use of a HTPB/PTHF blend is theoretically effective in enhancing the specific impulse and adiabatic flame temperature of an AN-based propellant. The AN/HTPB propellant left a solid residue on the burning surface, and the shape of the residue was almost the same as that of the propellant. On the other hand, an AN/HTPB/PTHF propellant did not leave a solid residue, and the burning rates of the $\mathrm{AN} / \mathrm{HTPB} / \mathrm{PTHF}$ propellant were almost the same as those of the AN/HTPB propellant. This was because some of the liquefied HTPB/PTHF binder covered the burning surface of the AN/HTPB/PTHF propellant. The burning rates of $\mathrm{AN} / \mathrm{HTPB} / \mathrm{PTHF}$ propellants with $\mathrm{ADC}$ were higher than those of AN/HTPB propellants with ADC. The addition of $\mathrm{ADC}$ to the AN/HTPB/PTHF propellant was required to clarify the effect of the blend binder on the improvement of the burning characteristics. The effect of the HTPB/PTHF blend on the increase of the burning rate was independent of the mass ratio of PTHF in the blend.

\section{Nomenclature}

$I_{\text {sp }}$ : Specific impulse, $s$

$T_{f}$ : Adiabatic flame temperature, $\mathrm{K}$

$\xi$ : Mass ratio of PTHF in binder, -

\section{Abbreviations}

AN: Ammonium nitrate

AP: Ammonium perchlorate

DTA: Differential thermal analysis

HTPB: Hydroxyl-terminated polybutadiene

IPDI: Isophorone diisocyanate

PTHF: Polytetrahydrofuran

TG: Thermogravimetry.

\section{References}

[1] G. P. Sutton, Rocket Propulsion Element, John Wiley \& Sons, New York, NY, USA, 1992.

[2] C. Oommen and S. R. Jain, "Ammonium nitrate: a promising rocket propellant oxidizer," Journal of Hazardous Materials, vol. 67, no. 3, pp. 253-281, 1999.

[3] Y. Hagihara, T. Ichikawa, H. Shinpo, and M. Suzuki, "Effects of chromium and cobalt compounds on burning rate of ammonium nitrate/hydroxyl-terminated polybutadiene composite propellants," Science and Technology of Energetic Materials, vol. 52, no. 6, pp. 390-395, 1991.

[4] H. Nakamura, M. Akiyoshi, K. Sakata, and Y. Hara, "Effect of metal complex catalysis of tetraaza-(14)-anurene on the thermal decomposition of ammonium nitrate and ammonium perchlorate," Science and Technology of Energetic Materials, vol. 61, no. 3, pp. 101-107, 2000.

[5] G. Singh and S. P. Felix, "Studies on energetic compounds: Part 36: Evaluation of transition metal salts of NTO as burning rate modifiers for HTPB-AN composite solid propellants," Combustion and Flame, vol. 135, no. 1-2, pp. 145-150, 2003.

[6] M. Quinn Brewster, T. A. Sheridan, and A. Ishihara, "Ammonium nitrate-magnesium propellant combustion and heat transfer mechanisms," Journal of Propulsion and Power, vol. 8, no. 4, pp. 760-769, 1992.

[7] V. P. Sinditskii, V. Y. Egorshev, A. I. Levshenkov, and V. V. Serushkin, "Ammonium nitrate: combustion mechanism and the role of additives," Propellants, Explosives, Pyrotechnics, vol. 30, no. 4, pp. 269-280, 2005.

[8] F. Nihal Tüzün and B. Zühtü Uysal, "The effect of ammonium nitrate, coarse/fine ammonium nitrate ratio, plasticizer, bonding agent, and $\mathrm{Fe}_{2} \mathrm{O}_{3}$ content on ballistic and mechanical properties of hydroxyl terminated polybutadiene based composite propellants containing 20\% AP," Journal of ASTM International, vol. 2, no. 6, pp. 233-245, 2005.

[9] M. Kohga and S. Nishino, "Burning characteristics of ammonium nitrate-based composite propellants supplemented with ammonium dichromate," Propellants, Explosives, Pyrotechnics, vol. 34, no. 4, pp. 340-346, 2009.

[10] T. Kuwahara and N. Shinozaki, "Burning mechanism of ammonium nitrate/aluminum composite propellants," Science and Technology of Energetic Materials, vol. 53, no. 3, pp. 131136, 1992.

[11] B. N. Kondrikov, V. E. Annikov, V. Y. Egorshev, L. DeLuca, and C. Bronzi, "Combustion of ammonium nitrate-based compositions, metal-containing and water-impregnated compounds," Journal of Propulsion and Power, vol. 15, no. 6, pp. 763-771, 1999.

[12] H. Murata, Y. Azuma, T. Tohara et al., "The effect of magnalium(Mg-Al alloy) on combustion characteristics of ammonium nitrate-based solid propellant," Science and Technology of Energetic Materials, vol. 61, no. 2, pp. 58-66, 2000.

[13] B. E. Greiner, R. A. Frederick, and M. D. Moser, "Combustion effects of C60 soot in ammonium nitrate propellants," Journal of Propulsion and Power, vol. 19, no. 4, pp. 713-715, 2003.

[14] T. Kazita, T. Saito, T. Yamaya, M. Shimoda, and A. Iwama, "Ignition characteristics of GAP/AN/AP-based solid propellants for low pollution at sub-atmospheric pressures," Science and Technology of Energetic Materials, vol. 57, no. 1, pp. 1-8, 1996.

[15] K. Kato and G. Nakasita, "Burning rate characteristics of GAP/AN propellant," Science and Technology of Energetic Materials, vol. 56, no. 3, pp. 130-134, 1995.

[16] Y. Oyumi and E. Kimura, "IM characteristics of GAP/AN composite propellents," Science and Technology of Energetic Materials, vol. 57, no. 1, pp. 9-13, 1996.

[17] M. Takizuka, "Combustion characteristics of GAP based composite propellants (I)-theoretical combustion performance and burning rate," Science and Technology of Energetic Materials, vol. 59, no. 4, pp. 181-191, 1998.

[18] C. Nakajima, T. Saito, T. Yamaya, and M. Shimoda, "The effects of chromium compounds on PVA-coated AN and GAP binder pyrolysis, and PVA-coated AN/GAP propellant combustion," Fuel, vol. 77, no. 4, pp. 321-326, 1998.

[19] P. Simões, L. Pedroso, A. Portugal, I. Plaksin, and J. Campos, "New propellant component, part II. Study of a PSAN/ DNAM/HTPB based formulation," Propellants, Explosives, Pyrotechnics, vol. 26, no. 6, pp. 278-283, 2001. 
[20] M. D. Judge and P. Lessard, "An advanced GAP/AN/TAGN propellant. Part I: ballistic properties," Propellants, Explosives, Pyrotechnics, vol. 32, no. 2, pp. 175-181, 2007.

[21] J. R. Goleniewski and J. A. Roberts, U.S. Patent 5783769Solid Propellant with Non-crystalline Polyether/Energetic Plasticizer Binder, issued on July 21, 1998.

[22] M. Kohga, W. Miyano, and T. Kojima, "Burning characteristics of polytetrahydrofuran-based composite propellant," Journal of Propulsion and Power, vol. 22, no. 6, pp. 1418-1421, 2006.

[23] M. Kohga and K. Okamoto, "Thermal decomposition behaviors and burning characteristics of ammonium nitrate/polytetrahydrofuran/glycerin composite propellant," Combustion and Flame, vol. 158, no. 3, pp. 578-582, 2011.

[24] M. Kohga, "Application of polytetrahydrofuran as a plasticizer of HTPB binder," Science and Technology of Energetic Materials, vol. 71, no. 3, pp. 77-82, 2010.

[25] M. Kohga, "Mechanical properties and burning characteristics of AP / HTPB composite propellant using polytetrahydrofuran as a plasticizer," Science and Technology of Energetic Materials, vol. 71, no. 5-6, pp. 145-150, 2010.

[26] K. Okamoto, M. Kohga, and K. Hasue, "Thermal behavior and tensile property of PTHF/HTPB blend," Science and Technology of Energetic Materials, vol. 70, no. 4, pp. 87-93, 2009.

[27] M. Kohga and K. Okamoto, "Thermal decomposition behavior of AN-based composite propellant with hydroxylterminated polybutadiene/polytetrahydrofuran blend as a binder," Science and Technology of Energetic Materials, vol. 72, no. 6, pp. 161-168, 2011.

[28] NASA Glenn's computer code Chemical Equilibrium with Applications, http://www.grc.nasa.gov/WWW/CEAWeb/. 

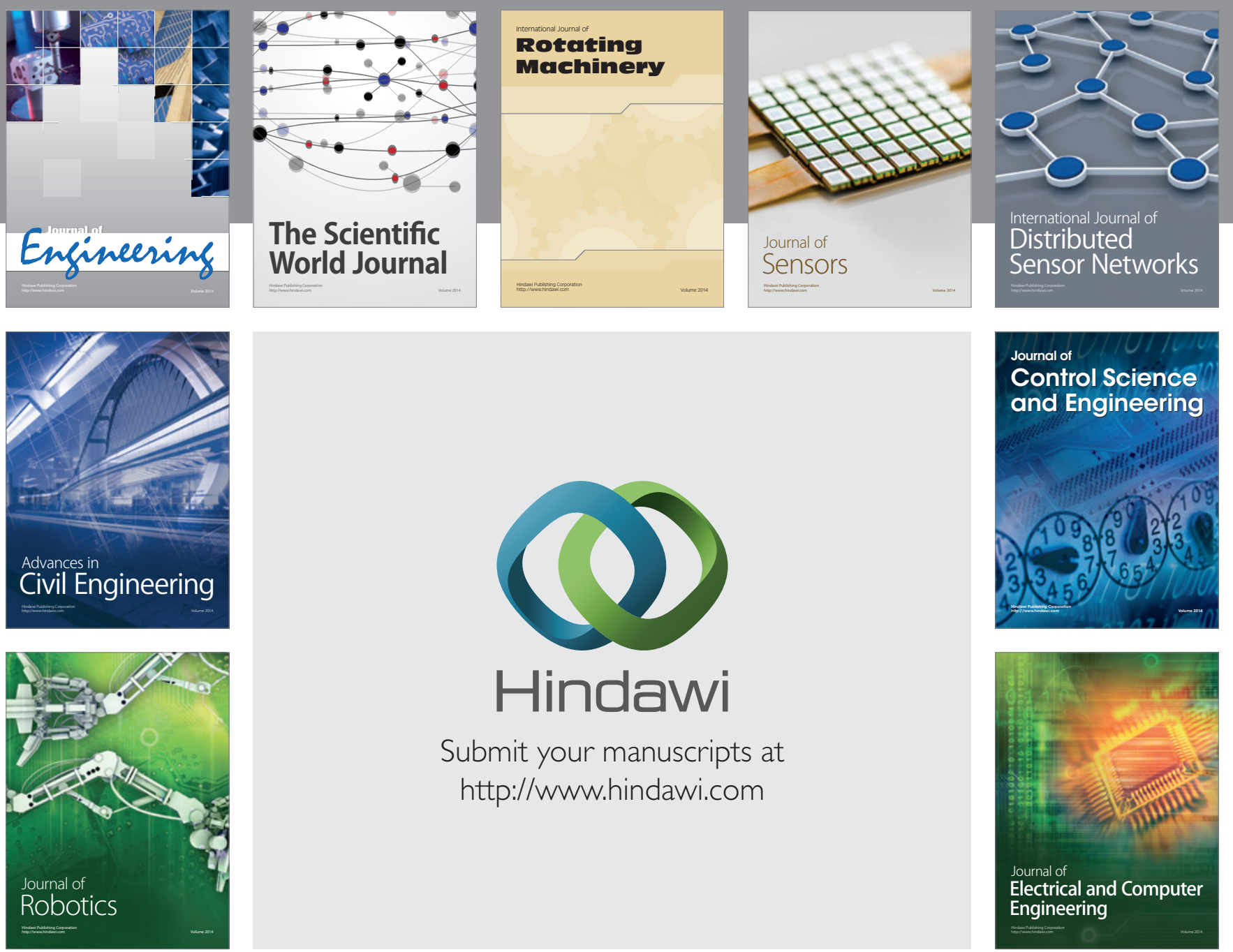

Submit your manuscripts at

http://www.hindawi.com
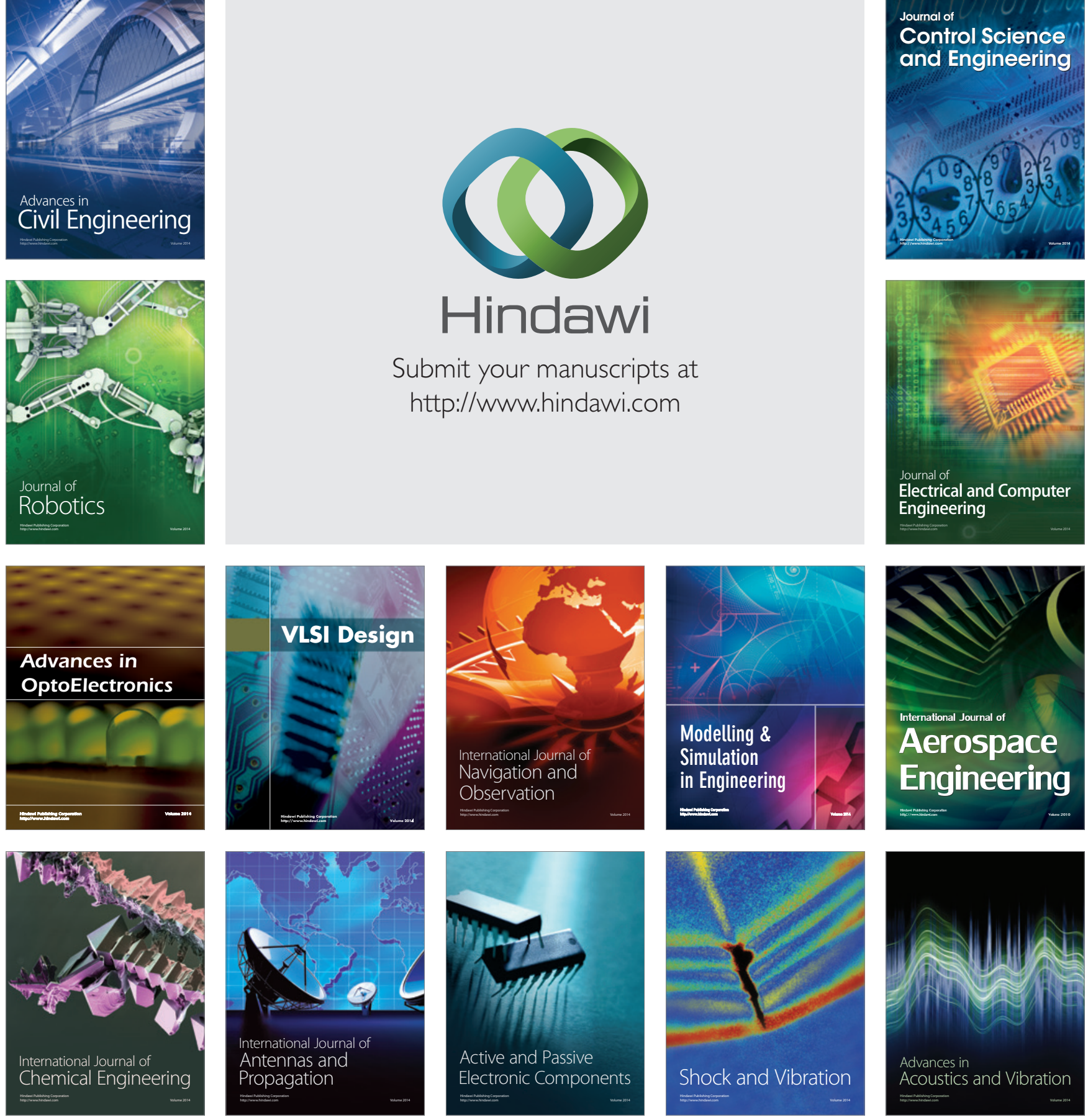